Diánoia, vol. 8, no. 8, 1962

\title{
LA FILOSOFIA DEL DERECHO DE ALFRED VERDROSS
}

I

Alfred Verdross, uno de los más grandes internacionalistas de nuestra época, es, al mismo tiempo, un gran filósofo del derecho. Kelsen y Verdross han dedicado su vida al estudio del derecho internacional y la filosofía jurídica. Pero entre ellos hay una diferencia de mucha importancia. Hans Kelsen, fundador de la Escuela de Viena, creador de la Teoria pura del derecho es, ante todo, jurista teórico, y ha llegado al derecho internacional por razones que derivan de su propia teoria. Verdross, por el contrario, es, ante todo, internacionalista, y ha llegado a la filosofía del derecho por razones oriundas del derecho internacional. Esta diferencia explica mucho de lo que tienen en común, y mucho, también, de lo que los separa. A ello hay que añadir la divergencia básica de sus cosmovisiones. Verdross es hombre de profunda convicción católica, mientras que Kelsen defiende una teoria relativista de los valores. Pero en lo personal son, desde hace casi medio siglo, entrañables amigos.

A los veintitrés años, el joven doctor Verdross ingresó al seminario privado de Kelsen en la Universidad de Viena. Partidario del neo-kantismo de Marburgo, la Teoria juridica pura fue para él fuente de inspiración. Su interés se orientó especialmente hacia la construcción teórica del derecho internacional, y el discípulo dirigió la atención del maestro, que en su primera y genial obra ${ }^{1}$ se había limitado a los derechos nacionales avanzados, hacia la importancia del derecho internacional desde el punto de vista de la teoría pura. Bajo esta influencia, Kelsen insertó el tratamiento de los problemas de esa disciplina en su teoría, y la inserción ganó más y más importancia, hasta resultar dominante en la obra inglesa de $1945 .^{2}$

Muy pronto hubo un cambio en la posición filosófico-jurídica de Verdross. ${ }^{4}$ Tal mudanza determinó su abandono de la filosofía neo-kantiana de Marburgo, la vuelta al realismo crítico, el paso del estudio de las formas al de los contenidos jurídicos, el retorno a la metafísica, a la ontología y la teoría de los valores y el decisivo viraje del positivismo jurídico al derecho natural tradicional y, especialmente, católico. Esta última vuelta refléjase

1 Hans Kelsen, Hauptprobleme der Staatsrechtslehre.

2 Hans Kelsen, General Theory of Law and State, Harvard University Press, 1945. (Traducción castellana de Eduardo García Máynez, México, 1950)

3 Véase el bosquejo de la biografía de Verdross por su discípulo, St. Verosta, en Voelkerrecht und rechtliches Weltbild. Festschrift für Alfred Verdross, Viena, 1960, pág. 1-29. 
en sus investigaciones de internacionalista, sobre todo en el tratamiento de los problemas relativos a la bona fides; a los principios generales del derecho reconocidos por las naciones civilizadas; al fundamento último del derecho internacional y a la última razón de validez del derecho en general. El mismo viraje explica sus tesis de que el derecho no puede ser un orden autosuficiente, de que está íntimamente ligado con la ética y de que en el internacional la actitud moral de respeto al derecho es más importante que la sanción. Por ello pudo escribir que su extenso Tratado de Derecho Internacional ${ }^{4}$ se inspira en la Escuela Española y, particularmente, en las ideas de Francisco Suárez.

- Mas para comprender bien a Verdross es preciso tomar en cuenta dos cosas: su derecho natural es muy moderado, muy restringido, y obedece a la tendencia conservadora que trata de conciliarlo con el derecho positivo. La mencionada obra es un estudio del derecho internacional positivo, vigente en la actualidad; por otra parte, pese a las ideas de derecho natural que formula en conexión con ciertos problemas fundamentales, su exposición es de las más positivistas que hay. No debe olvidarse que el autor pertenece a la Escuela de Viena, y que domina la técnica de la filosofía jurídica analítica.

Ya antes de 1998 Verdross había comenzado a estudiar las diferentes filosofías del derecho desde la Antigüedad. Después de la anexión de Austria por Hitler en $193^{8}$ se le prohibió enseñar filosofía jurídica en la Universidad vienesa. Entre $193^{8}$ y 1945 no publicó casi nada sobre temas de derecho internacional, a causa del nacional-socialismo y por no tener acceso a materiales extranjeros. Todo este periodo lo dedicó al estudio de la filosofía del derecho de la Grecia antigua. Sólo dos trabajos dio a la estampa durante ese lapso: uno sobre el pensamiento filosófico-jurídico de Heráclito ${ }^{5}$ y el bello opúsculo sobre los inicios de la filosofía europea del derecho y del Estado en Hesíodo. 6 Inmediatamente después de la guerra publicó el fruto de sus investigaciones de aquellos años, su libro sobre la filosofía del derecho y del Estado en la Antigüedad. ${ }^{7}$

A partir de 1945 nuevamente enseñó filosofía del derecho en la UniverSerra.)

4 A. Verdross, Voelkerrecht, $4^{\text {a }}$ ed., Viena, 1959. (Traducción castellana de Truyol

5 A. Verdross, "Die Rechtslehre Heraklits", Zeitschrift für Oeffentliches Recht, Viena, Vol. 22 (1942), pág. 498

6 A. Verdross, "Die Anfaenge der europaeischen Rechts-und Staatslehre bei Hesiod", ib., vol. 23 (1944), pág. 392. (Traducción castellana: "Los comienzos de la Teoría Europea del Derecho y del Estado", Diánoia, 1957, pág. 221.)

7 A. Verdross, Grundlinien der Antiken Rechts-und Staatsphilosophie, Viena, 1946; $2^{\mathrm{a}}$ ed., $i b, 194^{8}$. 
sidad dé Viena, y prosiguió su estudio de las filosofías júrídicas antiguas y modernas. Ya desde los veinte combate el voluñtarismo juridico y el positivismo. Después de 1945 aparecen diversos trabajos suyos sobre estos temas. Muy interesante el publicado en 1950 sobre la clasificación de los conceptos del derecho. ${ }^{8}$ Hay, dice, dos nociones de éste: la de la Antigüedad, la Edad Media y Santo Tomás lo considera como un orden razonable y moral y lo define en función de su contenido, a la vez que niega que la coacción le sea esencial; la otra es nominalista y voluntarista, y se basa en la voluntad del legislador y la fuerza fisica: es la definición del positivismo, enteramente formalista. Las dos definiciones - afirma- no cubren el mismo objeto, pero se cruzan: la segunda es aplicable a todos los órdenes coactivos, jurídicos o no, y no permite distiguir entre derecho y arbitrariedad, entre el Estado y una banda de ladrones. Jurídicos sólo pueden ser los órdenes coactivos que tienen contenido ético.

Criticamente debo decir que encuentro aquí una ambigüedad: ¿pretende Verdross sostener que la sanción, la fuerza física, si bien es necesaria, no es elemento esencial del derecho? En tal caso pregunto: ¿cuál es entonces la diferencia específica entre una norma jurídica y otra moral? ¿O es la coacción física elemento esencial, pero no suficiente, y el derecho debe además ser justo, para ser derecho? Pero en tal hipótesis habría que admitir que la mayor parte de la humanidad no ha vivido ni vive todavía bajo un orden jurídico, y que la vieja sentencia ubi societas, ibi jus es completamente falsa. Desde el punto de vista lógico pregunto también: ¿cómo puede haber dos distintos conceptos del derecho, si se admite que sus definiciones no se refieren al mismo objeto?

Ya en esos años introduce Verdross la distinción fundamental entre obligación juridica y de conciencia. Con ella se acerca mucho a mi propia posición, pues para mí el llamado derecho natural existe y obliga en conciencia, pero no es derecho, sino ética. No obstante, Verdross insiste, hoy todavía, en que es derecho, en el sentido técnico de esta voz.

En su artículo ¿Qué es derecho? ${ }^{9}$ hace un bosquejo de la actual crisis del positivismo y de la doctrina del derecho natural. Lo más valioso de ese artículo me parece ser la clara definición de "naturaleza", en el giro "derecho natural": la naturaleza de la doctrina del ius naturale no es la de las ciencias naturales, $n i$ la biológica del individuo humano, sino la esencial del hombre, tal como fue creado por Dios; esto - dice- es la metafísica católica: el fundamento católico del derecho está en la creación del mundo, en el orden normativo; y categóricamente añade: "Si la metafísica católica se niega, todo el derecho natural se derrumba."

8 A. Verdross, "Zur Klaerung des Rechtsbegriffes", Juristische Blaetter, Viena, vol. $7^{2}$ (1950), págs. 92-99.

9 A. Verdross, "Was ist Recht?", Wort und Wahrheit, agosto de 1953, págs. 586-594. 
En un largo artículo del año 1956 ofrece un panorama de las ideas filosófico-jurídicas contemporáneas. ${ }^{10}$ En tal estudio insiste en que el ius naturale no es un derecho ideal del paraíso, sino orden que se amolda a la esencia natural del hombre, tal como éste vive en la tierra.

Así como su gran Tratado de Derecho Internacional es fruto de los estudios y reflexiones de toda su vida, su obra sobre la filosofía del derecho occidental ${ }^{11}$ lo es de los estudios y reflexiones que a lo largo de su existencia ha dedicado a esta materia.

\section{III}

Tres puntos de vista circunscriben -como el propio Verdross lo explica en el Prefacio- el ámbito de la última obra. Se trata, en primer lugar, de una historia de la filosofía jurídica de Occidente, lo que excluye la consideración de las filosofías del derecho de culturas no occidentales. Limítase, en segundo término, a la Europa occidental y, por tanto, no incluye la filosofía juridica de la cultura de la Europa oriental, ruso-bizantina. Finalmente, no analiza la influencia de la filosofía juridica de Europa occidental en otros continentes que forman parte de la misma cultura.

Todo el libro está escrito desde el punto de vista filosófico del autor, que es el de la filosofía católica del derecho natural. En forma muy característica dice en el Prefacio que la restricción de su estudio al Occidente no significa que esta filosofía occidental — la verdadera - sea válida solamente para nuestra cultura. El derecho natural católico tiene validez universal; es inmutable en el espacio y en el tiempo, y el mismo para todos los pueblos, porque se basa en la naturaleza esencial del hombre, tal como fue creado por Dios. Verdross confía en que su obra puede ser el sillar de una futura filosofía del derecho, pero admite que sólo esa filosofía ecuménica podrá agotar toda la riqueza de la esencia natural del hombre.

Las convicciones personales del autor adviértense también en la elección de las escuelas filosóficas que trata, en la manera de tratarlas y en su actitud crítica ante ellas. Su libro es una historia de la filosofía del derecho de la Europa occidental, pero, al mismo tiempo, algo más. Es la filosofía jurídica del propio autor, "en perspectiva histórica". Verdross quiere exponer los problemas fundamentales de aquella disciplina, para llegar en diálogo con los diferentes pensadores occidentales, al verdadero conocimiento filosófico jurídico. A ello se debe que a los capítulos históricos siga otro, el

10 A. Verdross, "Gegenwartsstroemungen der Rechtsphilosophie", Wissenschaft und Weltbild, septiembre de 1956, págs. 161-171.

11 A. Verdross, Abendlaendische Rechtsphilosophie. Ihre Grundlagen und Hauptprobleme in historischer Schau, Viena, 1958, págs. $x, 270$. La traducción castellana de este libro, hecha por el Dr. Mario de la Cueva, será pronto publicada en México. Véase también la excelente reseña del Profesor Barna Horvart en: The American Journal of Comparative Law, vol. 6, 1959, págs. 535-538. 
último, que ofrece la apreciación crítica de los resultados y la filosofía del derecho del autor.

La mayor parte del trabajo está dedicada a la historia y valoración del derecho natural en sus diferentes matices y escuelas, que han aparecido históricamente durante el desarrollo de la cultura occidental desde la antigua Grecia, mientras que las filosofías "positivistas" tienen que contentarse con una exposición de poco más de 40 páginas. Hasta cierto punto esto es simplemente consecuencia del hecho histórico de que desde la Antigüedad hasta comienzos del siglo xix no hubo más que una filosofía del derecho, la del derecho natural, lo que hizo decir a muchos que con la victoria del "positivismo" esa filosofía "se acabó", para revivir solamente en la doctrina de Stammler.12 Pero este punto de vista es insostenible. Yo he defendido siempre la opinión ${ }^{14}$ de que hay tres ramas de la filosofía del derecho y que esas ramas existen actualmente: la analítica (que incluye a la teoría jurídica pura), la sociológica y la axiológica (derecho natural). La Escuela Analítica es de la mayor importancia para el juez, el abogado y el jurista teórico; concibe el derecho como norma, como sistema de normas, desde un punto de vista analítico, teórico, formal, constructivo. Pero para comprender cabalmente el derecho, en toda su complejidad, no es menos necesario estudiarlo desde los puntos de vista sociológico y axiológico. El enfoque sociológico de aquél es una ciencia causal; más que el derecho mismo, examina su creación, y ésta es naturalmente un hecho histórico, social y político: pertenece al reino del ser, mientras que las normas creadas en tal proceso se hallan insertas en el reino del deber. La filosofía sociológica considera también la efectividad del derecho, y aquí se trata igualmente de investigaciones causales. La filosofía jurídica axiológica, por su parte, critica el derecho, y toma como pauta de esta crítica una serie de normas extra-jurídicas: el derecho natural no es derecho, sino ética. Esta tripartición, deseo añadir desde luego, corresponde asimismo a las ideas de Verdross, quien ha reconocido la necesidad de combinar las tres direcciones, pese a sus grandes diferencias metodológicas, para comprender el derecho en toda su complejidad. La forma en que ha construido su gran Tratado de Derecho Internacional refleja esta preocupación, pues en dicha obra investiga los fundamentos sociológicos del derecho internacional y sus bases éticas, y en la parte principal expone, a la manera analítica, y en forma muy positivista, las normas de tal derecho actualmente en vigor.

La filosofía positivista (analítica y sociológica) suele estar en pugna con

12 En este sentido, por ejemplo, el libro del Profesor Carl J. Friedrich, Die Philosophie des Rechts in historischer Perspektive, 1955.

13 Véase mi estudio: "Zur Problematik der Rechtsphilosophie um die Mitte des 20. Jahrhunderts", Oesterreichische Zeitschrift für Oeffentliches Recht, vol. IV/1, 1951, págs. 1-26. Traducción portuguesa en: Revista da Faculdade do Direito, Săo Paulo, Vol. 46, 1952, págs. 43 sigs. 
el derecho natural. No puede negarse que, por regla general, asume una posición contraria a éste. Pero también es verdad que, desde cierto punto de vista, hay más afinidad entre la filosofía analítica y el derecho natural que entre las dos filosofías positivistas. La filosofía sociológica no ve en el derecho más que un hecho, ${ }^{14}$ posición ciertamente insostenible; pero la analítica y el derecho natural son ambas normativas y, en mi opinión, la verdadera diferencia entre las últimas radica en que la primera investiga normas jurídicas y la segunda normas éticas.

Por todas estas razones debo decir que el tratamiento que Verdross da a todas las escuelas "positivistas", sean analíticas o sociológicas, es demasiado breve y superficial. Esto se aplica a la Escuela Histórica -aunque la filosofía jurídica de Hegel sea tratada con amplitud-, a la filosofía marxista, a la de Nietzsche, a la Escuela Analítica de John Austin, a las escuelas sociológicas, ya se trate de Somló, de Horvarth o de los escandinavos (Olivecrona, Alf Ross), a la escuela fenomenológica e incluso a la Teoría Pura.

Resulta claro, por lo expuesto, que el libro versa fundamentalmente sobre la filosofía del derecho natural desde Hesíodo hasta Kant y su renacimiento en nuestra época. Ya en el Prefacio dice el autor que presenta las filosofías occidentales "con sus abismos, sus extravíos y las advertencias que de ello resultan". Y es muy natural que su propia posición, es decir, la del derecho natural católico, sea el criterio para distinguir entre las filosofías sanas y los abismos y extravíos. Ello explica, a la vez, que ciertas escuelas no se mencionen o sean muy brevemente tratadas, o la circunstancia de que el autor se oponga críticamente a las mismas. Hay, como es general en el derecho natural de nuestros días, una clara oposición al "positivismo", al voluntarismo, al relativismo y al escepticismo. El autor lleva todo su amor y dedica la exposición más larga al derecho natural griego-católico, siguiendo la línea histórica Hesíodo-Sócrates-Platón-Aristóteles-Cicerón-PatrísticaSan Agustín-Escolástica (Santo Tomás) y Neo-escolástica española (Vitoria y, particularmente, Suárez).

\section{IV}

Lo que he manifestado de manera general en el capitulo precedente trataré de mostrarlo ahora en detalle. En lo que atañe al periodo presocrático, Verdross concentra su atención en tres personajes: Hesiodo, Solón y Heráclito. Admira profundamente a Hesíodo, a quien ya había dedicado su bellísimo estudio de 1944. Reconoce, naturalmente, que éste no habla como filósofo del derecho, sino como poeta, dentro del cuadro de la mitología griega. Hesiodo introduce en sus poemas la noción de lo jurídico y ve en Zeus al protector del derecho en el Olimpo y en la Tierra. Dike, hija 
de Zeus, es quien lo ha traído a la Tierra desde el Olimpo. Este derecho abarca todo el orden cósmico, protegido por Zeus. Pero se trata de un orden doble: el de la naturaleza irracional y el de los hombres, a los que ese derecho, "el mayor de los bienes", ha sido dado. Consecuentemente, deben vivir de acuerda con "Dike" como corresponde a su naturaleza ( $\tilde{\eta} \vartheta 05)$. Verdross halla aquí los inicios de las ideas occidentales sobre el derecho: el orden cósmico protegido, aunque no creado, por Zeus, su doble manifestación, y el derecho que corresponde a la naturaleza del hombre y, por tanto, no puede ser interpretado como mero acto de voluntad. Este orden que se desdobla o bifurca, creado por Dios, es el que más tarde recibirá el nombre de lex aeterna. Kelsen ${ }^{15}$ ha subrayado cómo la interpretación de la naturaleza por el principio de causalidad es conquista bastante tardía en el desarrollo de la cultura humana. En los primeros tiempos la naturaleza era interpretada normativamente. Y Heráclito puede decir que si el sol se aparta del camino que le ha sido prescrito, recibirá el castigo de la Erinneas.

Si Hesiodo explica la fundación, Solón y Heráclito añaden otros dos elementos, igualmente esenciales, del derecho. Solón añade la fuerza. No la opone simplemente, como Hesíodo, al derecho, sino que distingue entre fuerza legal e ilegal. El derecho ha menester de la primera, para prevalecer contra la ilegalidad. Heráclito, a quien Verdross consagró su estudio del año 1942, añade un tercer elemento, de carácter dinámico, en contraste con el puramente estático que Dike representa. Según el Filósofo de Éfeso el derecho es producto de la lucha, es lucha. Verdross advierte críticamente, frente a Heráclito, que si bien tiene en la lucha su origen, no es la lucha misma, sino el orden que la supera. Por otro lado, detrás de la lucha visible descubre, en el pensamiento heracliteano, la "armonía escondida" en el eterno logos.

El periodo de los sofistas señala, para el autor, la crisis del pensamiento griego sobre el derecho. Mientras que en Grecia éste fue originalmente concebido como orden divino y cósmico, de índole objetiva, el periodo de la sofística -o "iluminismo griego"- inicia un viraje hacia el subjetivismo, el relativismo y el escepticismo. Los sofistas destruyen la fe en los dioses; atacan lo absoluto, tanto en el orden del saber como en el de la ética. El hombre es la medida de todas las cosas (Protágoras); no existe la verdad, sólo hay opiniones subjetivas; los juicios morales son de carácter convencional.

Verdross estudia el pensamiento de los sofistas en lo que respecta al "positivismo" y al "derecho natural". Protágoras es para él un "positivista moderado"; pero en Gorgias y en Trasímaco encuentra un relativismo jurídico radical, que degenera más tarde en puro escepticismo (Epicuro, Carneades).

$\mathrm{Al}$ inquirir si el derecho es justo "por naturaleza" o por creación positiva, los sofistas plantearon, de una vez para siempre, el problema del derecho

15 H. Kelsen, Society and Nature, 1943. 
natural, aunque no le dieron solución. Como en todo su libro, Verdross. muestra maravillosamente, con gran conocimiento de causa, el desenvolvimiento histórico de las ideas en la filosofía jurídica occidental; en este aspecto, la obra ofrece muchas consideraciones nuevas. Es interesantísimo comprobar cómo en los pensadores griegos ya existen, al menos in nuce, casi todas las filosofías que más tarde tendrán desarrollo en Occidente. En Calicles está ya la filosofía de Nietzsche. Alcidamas se pronuncia contra la esclavitud; Faleos defiende la idea de igualdad en la propiedad y en la educación; Licofrón ataca a la nobleza. Verdross reconoce plenamente la honda huella de la sofística. Los que pertenecen a la generación formada en la escuela de los sofistas tienen una cosmovisión muy diferente: compárese a Euripides con Esquilo y Sófocles; piénsese en Tucídides. Antes de los sofistas, los griegos atribuían al derecho origen divino y no dudaban de su justicia, como lo indica el famoso verso de Pindaro, según el cual es el derecho rey de todos. Pero después de los ataques de aquéllos, no bastaba ya probar que la ley había sido creada por el voto de la mayoría; era necesario probar también que era justa de acuerdo con la naturaleza. Verdross cita al respecto el diálogo entre Pericles y Alcibíades, en la cbra de Tucídides. La reacción contra la sofística tendrá, pues, que crear un derecho natural para justificar el positivo. El derecho natural creado más tarde en Occidente ha sido, en la mayoría de los casos, de corte conservador; el de tendencias revolucionarias es relativamente una excepción. ${ }^{16}$

El autor estudia de modo amplio y brillante el derecho natural ontológico-jurídico de Sócrates, Platón y Aristóteles y elogia las enseñanzas ciceronianas sobre la lex aeterna. Pero es patente que Platón y su mundo de las Ideas le inspiran la más profunda simpatía. El bien y la justicia no son algo que los hombres puedan crear con meras convenciones, sino que derivan de nuestra naturaleza razonable. No pueden, pues, tener cualquier contenido, sino que deben basarse, al menos en lo que a su fundamento concierne, en el ius naturale. En Aristóteles Verdross admira la doctrina del telos del hombre y de la naturaleza social de éste, pero prefiere no obstante a Platón, porque aquél niega, oponiéndose a su maestro, la trascendencia de las idẹas.

De las escuelas post-aristotélicas no habla del hedonismo epicúreo, y si menciona a Epicuro es solamente a causa de su escepticismo. Precisamente para mostrar la conexión histórica de las ideas filosófico-jurídicas de Occidente habría sido interesante detenerse en Epicuro un poco más. El Filósofo de Samos enseñó, contra los estoicos, que la virtud no es el fin último, sino sólo un medio para alcanzar la felicidad, que define como máximun de placer y mínimum de dolor: aquí tenemos ya, in nuce, la filosofía utilitaria inglesa. Verdross indica que en el desarrollo de las ideas iusnaturalistas ha tenido

16 La distinción entre derecho natural "conservador" y "revolucionario" ha sido in. troducida por Kelsen. 
gran influencia la discusión sobre si la naturaleza del hombre es originalmente buena o mala. Epicuro afirma que originariamente el hombre estuvo continuamente en lucha con sus semejantes (recuérdese el bellum omnium contra omnes, de Hobbes). Pero, continúa Epicuro, la lucha engendraba dolor y fue abolida con la creación del Estado. Su institución -afirma el mismo filósofo contra Platón y Aristóteles- no es de derecho natural, sino producto de un contrato concluido por razones utilitarias; aquí tenemos ya el antecedente de la doctrina del contrat social.

En lo que respecta a los estoicos, Verdross reconoce que su concepción central es la teoría del logos. Pero no se detiene mucho en el aspecto panteísta. La razón humana es para los discípulos de Zenón parte de la razón divina; la naturaleza estoica es, a un tiempo, la del hombre y la de las ciencias naturales. El autor alaba a esos filósofos su cosmopolitismo, pero les reprocha su fatalismo y su espíritu apolítico. A mi me parece que esta filosofía ha sido siempre considerada como preludio del cristianismo. La virtud es para los estoicos el fin último. Sabio es el hombre que ha domeñado todas las pasiones; el que no ha menester de nada; la askesis es una virtud. Pero la askesis, el desprecio de este mundo, de este "valle de lágrimas", es algo que existe también en el cristianismo antiguo.

Hay otra idea estoica de gran interés. Ya hemos citado la polémica sobre la bondad o maldad originarias de la naturaleza humana. Para los estoicos ésta fue originariamente buena, pero se corrompió más tarde. La filosofía estoica distingue en el hombre dos naturalezas y, consecuentemente, dos derechos naturales: la primera, la absolutamente buena del hombre perfecto, brilló durante la aurea aetas. ${ }^{17}$ Pero, pasada esa edad de oro, volvió al mal. La corrupción del hombre hizo indispensable el establecimiento del Estado y del derecho positivo con sus sanciones; a esta naturaleza corrupta corresponde un derecho natural imperfecto. Verdross subraya más tarde en su libro la importancia de esta idea de la bondad original de la naturaleza humana y de su posterior corrupción, importancia que no se pierde en la Iglesia católica y perdura entre católicos y protestantes. Pero el origen de la doctrina está en los estoicos; sólo que la edad de oro y la corrupción ulterior de que éstos nos hablan son reemplazadas por el paraíso y el pecado original.

\section{V}

Muchas veces se cree que el antiguo cristianismo simplemente aceptó el derecho natural de los griegos y, particularmente, el de los estoicos. Pero Verdross muestra, con investigaciones acuciosas e interesantísimas, que no fue asi, y que en el estudio del tema hay que incluir no solamente la filosofía,

17 "Aurea prima sata est aetas, quae vindice nullo, sponte sua, fidem rectumque colebat" (Ovidius) 
sino también la teología cristiana. Hace ver cómo hubo un derecho natural originalmente cristiano; que éste y el estoico coexistieron en un principio y que el cristianismo debía, ante todo, delimitarse frente a la filosofía pagana. Los griegos pensaron en todo tiempo, en lo que concierne al origen del Universo, que "siempre había sido así"; y en la antigua mitología griega los dioses eran inmortales, mas no eternos. El dios abstracto de Aristóteles "mueve sin ser movido", pero no es el creador. Para el cristianismo, Dios es creador del Universo. El hombre es siempre creatura, y su naturaleza no puede ser determinada sin referencia a la divinidad. La razón humana no puede ser, como para los estoicos, parte de la razón divina. Los antiguos cristianos tomaron el derecho natural, reconocido como tal por San Pablo, directamente del Nuevo Testamento. El Decálogo, dice Verdross, no es revelación, es derecho natural; el Decálogo solamente enseña sobre el derecho natural, pero no es fuente original. Con referencia a San Pablo Verdross subraya que el Decálogo, por esta razón, no es solamente obligatorio para ellos, para los cuales fue publicado como ley, sino para todos, incluyendo a los paganos, porque es de derecho natural que fue inscrito por Dios en el corazón de todos los hombres.

Después de fijar su derecho natural, el cristianismo pudo, en diálogo con la antigua filosofía del derecho, aceptar ciertas ideas del iusnaturalismo antiguo y, particularmente, estoico. Ésta fue la obra de la Patrística, que Verdross investiga en detalle. Aquí surge ya la controversia sobre si la naturaleza humana resultó solamente vulnerada o fue totalmente corrompida por el pecado original. Se distingue un derecho natural primario, absoluto (antes del pecado) y otro secundario, relativo (después del pecado original). Como he dicho, éstas son ya ideas estoicas; sólo que los estoicos hablaban de una época anterior y otra posterior a la edad de oro.

El autor desarrolla ampliamente la filosofía de San Agustín y el "derecho tri-escalonado" de Santo Tomás. Esta filosofía agustiniano-tomista fue ya combatida en la Edad Media. San Agustín dejó abierto el problema de si la lex aeterna se basa en la razón o en la voluntad de Dios (ratio divina vel voluntas Dei). Ya dentro de la Iglesia Católica, Guillermo de Occam elimina la razón divina y basa el orden cósmico únicamente sobre la voluntad de Dios. En consecuencia, no hay lex naturalis. Esta doctrina, comenta Verdross, constituye un voluntarismo nominalista $y$, trasplantada a la filosofía mundana, constituye la raíz del positivismo jurídico. Como reacción contra ella, otra doctrina, la de Gabriel Vázquez, elimina la divina voluntad y basa el derecho natural únicamente sobre la razón humana. Aquí tenemos el punto de partida del iusnaturalismo de Grocio y del puramente racionalista (droit de la raison).

El desarrollo del derecho natural católico sufrió la influencia de la Reforma. Para Lutero la naturaleza humana fue totalmente corrompida por 
el pecado original; consecuentemente, no se puede admitir una verdadera lex naturalis. El orden creado por Dios después del pecado casi se identifica con el derecho humano positivo. ${ }^{18}$

Después de tantas aberraciones, el primer renacimiento de la philosophia perennis de Santo Tomás aparece en la Neo-Escolástica Española. Verdross estudia ampliamente y con amor la filosofía del derecho de Vitoria y, particularmente, la de Francisco Suárez. Esta última constituye para él la coronación del pensamiento filosófico español y le parece básica tanto como filósofo del derecho cuanto como internacionalista.

\section{VI}

Como introducción a la filosofía del derecho de los tiempos modernos Verdross hace una breve pero magnífica investigación de las fuerzas e ideas que transformaron la Edad Media hasta llegar a los tiempos modernos: la desintegración de la Communitas Christiana de la Edad Media, la formación de un pluralismo de Estados soberanos en la Europa occidental. Todo condujo a la concepción del Estado como un mecanismo político y a la doctrina de la ragione di stato, desarrollada en las obras de Maquiavelo. Al mismo tiempo vemos el origen de las modernas ciencias naturales matemáticas, la doctrina de Francis Bacon, el método inductivo, la verficación por el experimento, la insistencia sobre el principio de causalidad. Todo fomenta el positivismo jurídico. La filosofía moderna, desde Descartes hasta Kant, abandona la filosofía antigua-medieval del ser, la filosofía realista, para reemplazarla por una filosofía del Yo que crea un idealismo que parte del sujeto y sustituye la contemplación del ser real del mundo por las fuerzas de la razón constructora del mundo. Esta antipatía contra la filosofía del Yo, contra el método de Bacon, quien - según el autor- ha aumentado mucho nuestro conocimiento, pero ha disminuido nuestra conciencia, es fundamental para la filosofía de Verdross. En la Antigüedad el hombre aparece como miembro de la polis, máś tarde de la cosmópolis. Pero en los tiempos modernos reina el individualismo, que inspira el humanismo italiano y - de un lado muy diferente-- el protestantismo, luterano particularmente, que considera la naturaleza humana totalmente corrompida por el pecado original. El derecho natural objetivo, greco-católico es seguido por un derecho natural subjetivo, o para decirlo en inglés: no se trata ya del "natural law", sino de "natural rights".

Verdross estudia criticamente este derecho natural "clásico", pero con mucho cuidado. Lo clasifica en tres escuelas. Hay, en primer lugar, el dere-

18 "El derecho natural luterano es una glorificación radical y conservadora de las autoridades que tienen el poder" (E. Troeltsch, "Das stoisch-christliche Naturrecht und das moderne profane Naturrecht", Historische Zeitschrift, vol. 106, 1911, pág. 256. 
cho natural de Grocio, quien, al mismo tiempo, escribió el primer tratado de derecho internacional. No hay duda de que el jurista holandés está aún fuertemente influido por el derecho natural católico de la Edad Media. Pero, como protestante, aunque fiel cristiano, lo secularizó con su famosa sentencia de que el derecho natural sería válido aun cuando no hubiera Dios. Verdross piensa que Grocio, al escribir esta frase, quería subrayar la evidencia del derecho natural. Pero, en todo caso, elimina a Dios y hace de la razón humana, no un simple medio para hallar las normas inscritas por Dios en el corazón de todos los hombres, como en el derecho natural medieval, sino la base del derecho natural. No se puede decir que haya salvado el iusnaturalismo medieval en los tiempos modernos; lo ha alterado completamente, al quitarle el fundamento absoluto, y lo ha convertido en algo puramente hipotético. El derecho natural católico que, según las palabras de Santo Tomás, es "participatio creaturae humanae in lege aeterna", está basado absolutamente en la fe católica. Desde el punto de vista filosófico estoy completamente de acuerdo con Jacques Maritain, quien escribe que Grocio no pudo "secularizar" el derecho natural católico sin eliminar el verdadero corazón de esta doctrina.

Después de Grocio hubo dos escuelas del derecho natural clásico: la del derecho natural "naturalista" y la del iusnaturalismo puramente racionalista. La primera rompe con la doctrina aristotélico-tomista de la naturaleza social del hombre, de su recta ratio, del Estado basado sobre el derecho natural, y parte del hombre como animal social en estado de naturaleza, es decir, la del hombre en el sentido de los instintos, y de la creación artificial del Estado por un "pacto social". El autor estudia seguidamente las ideas de Hobbes y de Spinoza; discute después las de Locke, quien crea de nuevo la idea democrática y la de los "derechos inherentes" al hombre. Siguen el estudio de Thomasius, el derecho natural revolucionario de Rousseau y el utilitarista de Bentham.

Las páginas dedicadas a Pufendorf, Leibniz y Wolff discuten la escuela puramente racionalista del derecho natural clásico. Como remate de esta larga historia del derecho natural de Occidente el autor hace un amplio análisis de la filosofía moral de Kant, aunque con ciertas reservas críticas. Sabemos que está contra la filosofía del Yo; quiere también restringir la estricta separación entre "ser" y "deber ser".

Es interesante notar que Grocio distingue en su derecho internacional un derecho internacional naturale y un derecho internacional volunta. rium. La escuela grociana lo sigue en este punto. Pero más tarde hubo otras dos escuelas de derecho internacional: una elimina el derecho positivo completamente, de manera que el derecho internacional resulta exclusivamente derecho natural (Pufendorf), mientras que la otra elimina el derecho natu- 
ral completamente y crea la escuela puramente positivista del derecho internacional (Johann Jakob Moser).

\section{VII}

Llegando a la filosofía del derecho de la época presente, Verdross reconoce que muchas corrientes de la filosofía moderna, como el empirismo, el positivismo, el nominalismo, el materialismo, no se han extinguido todavía. Pero tiene la impresión de que la actual filosofía del derecho se caracteriza por una vuelta al ser como punto de partida de la especulación filosófica, en sentido contrario al de la filosofía desde Descartes hasta el neo-kantismo de Marburgo. Cita a Nicolai Hartmann como iniciador de una filosofía realista, cuya tarea consiste en llegar al conocimiento del mundo real. Su filosofía es, pues, ontológica; pero no está de acuerdo con Hartmann, porque éste rechaza la imagen teleológica del mundo y repudia la razón divina, que es supuesto ineludible de toda teleología.

La vuelta a la ontología va unida a un retorno a la teleología, a la metafísica, a la moderna teoría de los valores y a la Neo-Escolástica. Interesantísimo es el capítulo sobre el cambio del mundo en las ciencias naturales matemáticas de hoy. Estas investigaciones - dice Verdross- han mostrado que el universo tiene una historia que puede ser seguida científicamente hasta sus comienzos. El resultado de estas investigaciones - añade- no demuestra la creación del mundo por Dios, pero muestra que es compatible con los resultados de las ciencias naturales matemáticas de hoy.

Verdross explica el renacimiento del iusnaturalismo por el cambio de la filosofía en general. Pero me parece que no insiste bastante sobre otras causas de ese renacimiento. El siglo xIx fue, comparativamente, siglo de paz, de codificación del derecho positivo, lo cual explica ya la predominancia del positivismo. El siglo $\mathrm{xx}$, siglo revolucionario, de transformación rápida, de cambio radical, de crisis, plantea, en primer lugar, tanto en los derechos nacionales como en el internacional, problemas de reforma, de política jurídica para los cuales el positivismo no tiene respuestas. En estricta conexión con esta causa está el hecho de que el siglo xix fue optimista, y creía que el derecho positivo se hallará siempre, generalmente hablando, en armonía con el llamado natural. Como ya ha dicho Heinrich Rommen y afirma también Verdross, en tiempos normales el derecho positivo basta; es solamente en los de horror cuando la conciencia se rebela contra él y la enseñanza de que "puede tener cualquier contenido". Ahora bien: los nuestros no son tiempos normales, todo lo contrario; estamos condenados a vivir una época de horrores insólitos, campos de concentración, cámaras de gas, torturas y actos de barbarie, más terribles que nunca, a causa de los progresos tecnológicos. Es ésta una causa muy poderosa del renacimiento del ius naturale. 
Verdross ofrece, pues, el panorama' dé este renacimiento de la "filosofia natural del derecho": superación del relativismo justifilosófico, filosofía existencialista del derecho y neo-tomismo.

La última parte del libro valora críticamente los resultados y contiene la filosofia del derecho del autor. La filosofía jurídica occidental es para Verdross una totalidad que se ha desplegado en parte orgánicamente; en parte dialécticamente. En la segunda mitad del siglo xIx, dice, todas estas antinomias desembocan en la resignación de la teoría que se contrae al hecho de la positividad y se contenta con descubrir las formas universales de lo jurídico, pero considerando como su contenido únicamente el de las prescripciones positivas. El deber jurídico es despojado de su fundamento ético. Pero el positivismo, para resolver el problema del fundamento del derecho positivo, debe presuponer una "norma fundamental", meta-positiva, a fin de poder concebir los actos de voluntad de los gobernantes como normas obligatorias. En el siglo $\mathrm{xx}$, la filosofia del derecho ha entrado, según Verdross, en una nueva fase: el renacimiento del derecho natural. Admite, es cierto, que todavía hoy existen dos grupos de adversarios del derecho natural, aunque esos dos grupos difieren mucho entre sí: los agnósticos y escépticos, por un lado, y ciertas sectas protestantes que, debido a su creencia de que la naturaleza humana fue totalmente corrompida por el pecado original, niegan aquel derecho y sólo reconocen la revelación divina.

Para Verdross el derecho natural únicamente puede ser derivado de la naturaleza humana, tal como fue creada por Dios. Los llamados "sentimiento jurídico" (Coing) o "conciencia del derecho" son demasiado subjetivos para derivar de ellos normas legales básicas dotadas de objetividad. La sana razón del hombre puede ser un medio para reconocer el derecho natural inscrito por la mano del Creador en el corazón de todos nosotros, pero no la base misma de ese derecho. Si no puede ser derivado sino de la naturaleza del hombre, su esencia y contenido estarán formados por las normas que corresponden a la naturaleza humana espiritual y social. Las doctrinas que parten solamente de la naturaleza zoológica del hombre o que sólo ven en él un ser social, no pueden ser exactas. Sólo un derecho natural con base antropológica total puede llegar a la verdad. Dentro de este iusnaturalismo hay dos variantes: la antropocéntrica y la teocéntrica. Verdross estudia la teoría de los valores de Kraft, ${ }^{19}$ quien construye una axiologia puramente empírica y llega al resultado de que ciertos valores derivan con necesidad absoluta de la organización del hombre. La teoría de Kraft, dice Verdross, corresponde a la

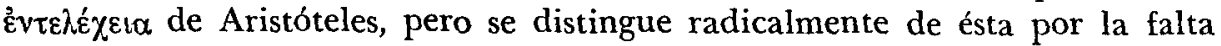
de un fundamento metafísico. El que Kraft propone es puramente hipotético. Por otro lado, la circunstancia de que Kelsen haya tenido lógicamente que reconocer como fundamento del derecho una norma ultra-positiva, y el

19 V. Kraft, Die Grundlagen einer wissenschaftlichen Wertlehre, $2^{\mathrm{a}}$ ed., 1951. 
hecho de que esta "norma fundamental" sea solamente hipotética, permiten a Verdross conciliar la Teoría Pura con su derecho natural. Como Santo Tomás, Suárez y casi todo el neo-tomismo moderno, Verdross restringe el derecho natural eterno $e$ inmutable a unas cuantas normas muy generales $y$, en consecuencia, un tanto vagas, mientras que la regulación detallada debe ser realizada por el derecho positivo, de acuerdo con las circunstancias de lugar y de época, que normalmente cambian. Verdross rechaza la idea del padre jesuita Josef Fuchs, de que el derecho natural no da solamente unos cuantos principios de máxima generalidad, sino que regula también las situaciones particulares. Como única contribución del derecho natural "clásico", Verdross incorpora a su doctrina la idea de los "derechos del hombre", que estudia en sus raíces filosóficas y sociológicas. La dignidad humana es enseñanza fundamental católica y tiene su base última en el hecho que todos los hombres somos hijos de Dios.

\section{VIII}

Este análisis, estoy seguro, evidencia el gran mérito de la obra de Verdross: no sólo como historia del pensamiento jusfilosófico occidental, sino como filosofía del derecho del autor. Ya en el Prefacio dice que el derecho basado en la naturaleza común del hombre, tal como fue creado por Dios, no es válido solamente para Occidente. Este problema de la comunidad de valores tiene gran importancia para la situación crítica del derecho internacional de nuestros días. El difunto profesor Brierly, de la Universidad de Oxford, ya había considerado que la ausencia de valores comunes en la llamada "comunidad internacional" es una de las causas más importantes de que tal comunidad internacional no sea una verdadera comunidad, sino simplemente una sociedad, lo que al propio tiempo hace imposible un derecho internacional verdaderamente progresivo, vigoroso y eficaz. Actualmente hay un abismo ideológico entre el mundo democrático y el totalitario. Además, la "comunidad internacional" ha llegado a ser ahora, por primera vez en la historia, verdaderamente internacional, y no está ya casi exclusivamente dominada por las naciones de cultura occidental. En la escena internacional aparecen pueblos de culturas no occidentales. ¿Hay normas éticas supremas que sean comunes a todos estos Estados? 20 Se trata de normas éticas, y no solamente, como creen los partidarios de las "escuelas realistas", de "preferencias" que podamos comprobar sociológicamente, de modo estadístico. El profesor Northrop, de la Universidad de Yale, ha escrito libros sobre

20 Véase: Proceedings of the Natural Law Institute, V, 1953 (Catholic Notre Dame Law School, South Bend, Indiana, USA) En ese Instituto han hablado sobre derecho natural sabios judios, mahometanos, hindúes y adherentes del Confucianismo. Quiero recordar también la Revista: Natural Law Forum, publicada desde $195^{6}$ por la misma Escuela. 
los sistemas de valores de las diferentes culturas no occidentales. Es partidario del "derecho viviente" del austriaco Ehrlich, quien ha ejercido gran influencia sobre los realistas norteamericanos. Pero en su último libro ${ }^{21}$ ve y plantea el problema correctamente: escuelas analíticas y sociológicas, dice, son incapaces de establecer una escala normativa, para determinar el "deber ser" del derecho positivo. Se trata -añade- de la "valuation of ends in terms other than political expediency, in terms other than the sociologists 'description of what is being done'". Pero no puede resolver el problema que plantea correctamente, porque cree que a esta escala normativa se puede llegar aplicando métodos de las ciencias naturales.

Además en la actualidad nos enfrentamos a otro problema. Se dice que los valores absolutos deben tener un fundamento metafísico. Pero la metafísica no puede ser ciencia. Por tanto, cientificamente, sólo puede haber valores relativos. Ésta es la postura kelseniana. Kelsen siempre ha rechazado el neopositivismo del "Círculo de Viena". No niega los valores, ni su importancia para el derecho positivo, ${ }^{22}$ pero sí niega lo absoluto. Para él no hay, por ejemplo, una justicia, sino muchas justicias diferentes, a menudo discrepantes $u$ opuestas. ¿Podemos, pues, científicamente, superar el relativismo axiológico? 23

Deseo añadir algunas líneas, para fijar mi posición frente a la filosofía del derecho de mi amigo Verdross. El profesor Ploechl, ${ }^{24}$ de la Universidad de Viena, ha escrito que Verdross y yo no tenemos, en materia de derecho internacional, la misma base filosófica, porque yo me inclino más al positivismo. Pero la verdadera situación es más complicada. Yo soy un positivista moderno, es decir, en primer lugar, no comparto el positivismo ingenuo del siglo xIx, sino el crítico del siglo Xx. Además, no soy positivista filosófico, sino jurídico. El positivismo jurídico restringe el término "derecho" a las normas del derecho positivo, pero no niega que haya normas superiores. Verdross reconoce esta diferencia; él mismo cita una alocución de la más alta autoridad católica, en que el Papa Pío XII hace esta diferencia y declara inocente al positivismo jurídico.

Ahora bien: yo soy positivista crítico y jurídico. Pero "derecho" natural es un "misnomer"; no se trata realmente de derecho, sino de ética. Yo siempre he sostenido que los valores éticos y religiosos son más altos que los del derecho. Verdross está convencido de que el derecho natural tradicional es válido para todos los hombres. Pero ni siquiera esta convicción resuelve el problema de si es posible alcanzar cierta comunidad de valores en la comu-

21 Northrop, The Complexity of Legal and Ethical Experience, Boston, 1959.

22 Véase su último libro: H. Kelsen, Reine Rechtslehre, Viena, 1960.

23 Véase A. Brecht, Political Theory. The Foundations of $20 t h$ Century Political Thought, 1959, y el artículo de A. Means Jr., "Scientific Legal Theory and Arnold Brecht", Virginia Law Review, 47/2, March 1961, págs. '264-271.

24 En la Festschrift für Verdross, obra citada en la nota 3, pág. $5^{2}$. 
nidad internacional, como base de un derecho internacional más progresivo y eficaz. Personalmente no soy un relativista en materia axiológica. Como occidental de nacimiento, estoy de acuerdo con Verdross en que la ética católica es la más alta del mundo. Y me siento especialmente cerca de él en esta época de crisis, en que nuestra cultura occidental, greca-cristiana, está empeñada en una lucha de vida o muerte, y en que el reconocimiento y la defensa de sus valores es para ella condición de supervivencia.

Como se ve, poco es lo que me separa de la filosofía del derecho de Verdross. Él mismo ya está muy cerca de mi posición; habla de obligaciones de conciencia y de crítica ética del derecho; pero no da el último paso; todavía considera el derecho natural como derecho. Se podría decir que lo que nos separa es sólo una cuestión terminológica; sin embargo, juzgo que es algo más. El reconocimiento de que el llamado derecho natural no es derecho, sino ética, es para mí básico. Naturalmente que tal reconocimiento ya ha sido defendido muchas veces; pero resulta particularmente importante el hecho de que esta enseñanza haya sido plenamente confirmada por una autoridad neo-tomista de la Universidad Católica de Lovaina, el profesor Jean Dabin, ${ }^{25}$ quien escribe claramente y $\sin$ ambigüedad:

"Au binôme: droit naturel-droit positif il faut substituer celui de: morale-droit."

JOSEF L. KUNZ 